\title{
INHIBITORS OF TALENT RETENTION IN UAE PUBLIC HEALTHCARE
}

\author{
Shamsa Al Mheiri \\ Abu Dhabi University \\ Fauzia Jabeen* \\ Abu Dhabi University \\ Salam Abdallah \\ Abu Dhabi University
}

\begin{abstract}
This paper aims to identify and rank factors that impact talent retention in the public healthcare sector in the United Arab Emirates. The study employs Analytic Hierarchy Process (AHP) methodology to rank factors affecting talent retention. Our AHP model features 6 criteria and 19 sub-criteria extrapolated from the literature. Data collection occurred through interviews with 18 employees, arranged into three groups: administrators, medical staff, and medical researchers from UAE-based public healthcare units. Collected data were interpreted and a priority vector assigned to each criterion and sub-criterion. It was found that recognition was the most important factor for retaining employees from the view of administrators. Career development and succession plan has the highest priority factor for medical staff. For researchers, sustainable practices were the most important factor for employee retentions. The paper suggests that differentiating retention strategies from one sample group to the other based on their profession helps policymakers and strategic HR planners deal with different pools of talent. The paper covers groups from the UAE public healthcare sector, offering material for further comparative studies with private sector, other service sectors, or from the healthcare sector in other regions. Employee retention in the UAE public healthcare sector is becoming a challenge, since the private sector often provides better employment opportunities. This paper provides a number of priority-ranked motivating factors based on different specialisms, to help employee retention.
\end{abstract}

Keywords: AHP Model, Employee Retention, Talent Retention, Human Resource Management, United Arab Emirates (UAE).

Received: 21 August 2019

Accepted: 30 July 2020

https://doi.org/10.33736/ijbs.3163.2021

\section{INTRODUCTION}

Employee retention is the ability of an organization to retain its employees (Deo, 2014). It means the implementation of policies and practices that encourage the employees to be more attached to the organization and stay longer time (Francis, 2014). Retaining talented and loyal employees is considered one of the major challenges facing private and public organizations in the Gulf Cooperation Council (GCC) countries in general, and in the United Arab Emirates (UAE) in

\footnotetext{
- Corresponding author: Professor of Management, College of Business, Abu Dhabi University, Abu Dhabi, UAE; Email: fauzia.jabeen@adu.ac.ae
} 
particular (Suliman \& Obaidli, 2011; Singh, Jones \& Hall, 2012). Losing talent entails high costs that organizations need to face; for example, Ernst \& Young estimates it costs approximately $\$ 120,000$ to replace 10 professionals (Laddha, Singh, Gabbad, \& Gidwani, 2012). Typically, turnover costs for entry-level employees amount to between 30 and 50\% of their annual salary, which rises to $150 \%$ of annual salaries for middle-level employees, and up to $400 \%$ of annual salaries for upper-level, specialized employees. In the UAE, the high rates of employee turnover result in a high annual cost at about $\$ 2.7$ billion (Gulf News, 2008). These figures account for increased efforts by organizations to retain their employees, since losing talented personnel gives rise to direct and indirect costs.

Employee retention was investigated in health sectors by many researchers (Zafar \& Siddiqui, 2019; Weyman, Roy \& Nolan, 2019). For example, Ohunakin, Adeniji, Ogunlusi, Igbadumhe, and Sodeinde (2020). They found that when managers provide support, career development for the workforce, it will enhance the knowledge sharing and increase employee retention. On the other hand, there are few studies in the UAE that investigated the factors impacting employee retention and most of them focused on private sectors (Khan, 2018) such as Islamic banking (Suliman \& Obaidli, 2011) and oil and gas industry (Singh et al., 2012). Karam, Ab Yazid, Khatibi, and Azam (2017) investigated the relationship between human resource management and management retention in aluminum industry. Therefore, this study is considered the first study to investigate the employee retention in the health sector in the UAE. According to the Health Authority of Abu Dhabi (2012), the healthcare sector in the Emirate of Abu Dhabi has been undergoing sustained expansion since 2008. As a result, this market has opened up to expert workforce both in the private sector, and with public providers of healthcare services. This development has intensified the challenge of sustaining employee engagement and managing talent retention in public healthcare organizations, as they strive to compete with private providers.

In view of the above, this paper's contribution is to help formulate efficient strategies for sustaining organizational performance through talent retention. In order to do this, we consider a number of factors impacting employee retention, which are positively related to employee engagement (Muthuveloo, Basbous, Ping, \& Long, 2013). According to Brunges (2014), one of the biggest factors that increase employee commitment, engagement, and job satisfaction is workplace culture. Therefore, it is worth investigating what factors affect organizational culture in the public healthcare sector.

As a consequence, our study focuses on the culture of excellence that the UAE government is trying to facilitate in public and private sectors entities, through different award schemes. These include: the Abu Dhabi Award for Excellence Performance (ADAEP) Program, the Dubai Quality Award (DQA), and the Shaikh Khalifa Excellence Award (SKEA) Program. These schemes seek to incentivize a culture, in government organizations, of promoting best practices and obtaining recognition for complying with those. The model for excellence adopted by the UAE government is that of the European Foundation for Quality Management (EFQM), which supports the achievement and maintenance of superior performance levels that exceed stakeholder expectations. In this paper, we define an organizational culture that leads to excellence in performance a 'culture of excellence'.

Establishing a culture of excellence also reverberates on the workforce retention rate due to stronger employee commitment, engagement, and job satisfaction. Enhanced retention rates, 
sharing of knowledge, and recognition have been reported to raise individual and organizational performance (Suresh, 2014). Kassem, Ajmal, and Khan (2016) have also observed that standardization, as a strategy to support growth of the UAE economy and of the country's international competitiveness, demands alignment of employee retention practices to a framework of excellence, with the goal of sustaining organizational performance. In addition, the UAE government has committed to a robust framework of assessment of its organizational performance, with a view to achieving the UAE Federal Vision 2021 and the Emirate of Abu Dhabi Vision 2030 of becoming among the best governments in the world and that was witnessed during the time of managing responses to certain health crisis.

The UAE government has played a vital role in dealing with crisis of Covid-19 virus and according to the competitiveness report for 2020, the UAE came in the 9th place globally for effective and efficient leadership to restore its health systems (Federal Competitiveness and Statistics Authority, 2020). All these indices can't be achieved without having an inspirational leadership that unify the efforts towards increasing knowledge sharing and enhancing organizational performance (Al Dari, Jabeen \& Papastathopoulos, 2018). For example, the effective communication tools between the crown prince of Abu Dhabi and the medical staff to ask for their inquiries, check up on their safety and evaluating their dedication and efforts at covid-19 time, will enhance the retention in public health (Nasrallah, 2020).

To summarize, a number of factors speak of the increasingly pivotal role that talent retention is going to play in raising organizational performance. In this context, all public hospitals in the UAE are required to comply with the framework adopted as a reference for the excellence awards, which draw on the EFQM model. The paper therefore considers the practices spelled out in the model, as factors worth assessing.

The selection of employee retention strategies is supported by many indicators of organizational performance, such as knowledge retention, efficiency, productivity, customer satisfaction, employee engagement, and job satisfaction. Indicators such as these help organization continuously to improve their performance (Cappelli, 2000; Ton \& Huckman, 2008; Hill, 2009; Davidson \& Wang, 2011; Hausknecht, Trevor, \& Howard, 2009; Suresh, 2014; Brunges, 2014; Muthuveloo et al., 2013; Laddha et al., 2012). In this paper, we aim to determine factors that affect employee retention in the UAE public healthcare sector, in order to build a framework for ranking them through the AHP model. The researcher chose AHP because it is the most suitable tool to prioritize such factors to meet research objectives. AHP is a multi-criteria decision making method which measures and prioritize intangibles, thereby allowing research to include practitioners' experience for the identification and ranking of performance improvement opportunities (Jabeen, Mehmood, \& Mehrajunnisa 2020). While employee retention factors feature prominently in the literature, factors that affect more specifically employee retention in the UAE public healthcare sector have received scant attention. In view of this, our paper tries to bridge that gap by (1) identifying the factors impacting employee retention in the UAE public healthcare sector, and by (2) developing a framework to rank the factors affecting organizational performance through the AHP model. 


\section{LITERATURE REVIEW}

\section{$2.1 \quad$ Retention}

Retention is the intentional effort, by an organization, to facilitate an environment capable of retaining employees long term (Samuel \& Chipunza, 2009). Deo (2014) defines 'employee retention' as the ability of an organization to retain its employees. He stresses that hiring knowledgeable and skillful people is essential, but their retention can be even more important. Ipek and Arzu Kalemci (2012) concur that the costs of employee turnover can be particularly high. In the UAE, employee turnover costs organizations about AED 9.9 billion per year (Suliman \& Obaidli, 2011; Iqbal, 2010). This is the main reason why companies aim to retain their employees: to protect their investment in personnel because it is costly to recruit and train new employees. When experienced employees leave an organization, performance is impacted, in the first place, by the departure of the employee and, secondly, by the time it takes to integrate a replacement employee (Krishnan, Warier, \& Kanaujia, 2013; Surbakti \& Ta'a, 2016). Employee turnover often results in a drain on management time and creates pressure on workforce planning. The impact of turnover is further compounded by intangible costs, such as the negative impact on employee morale, adverse effects on social capital, and erosion of organizational memory (James \& Mathew, 2012). Finally, high turnover rates will increase the workload on remaining employees (Guha \& Chakrabarti, 2015), while replacements will need to be inducted, trained and developed, at an additional cost (James \& Mathew, 2012).

In view of the foregoing, organizations strive to create an environment in which one would be willing to remain. Here, the very first step towards effective retention is accepting the reality that movement of employees is not only governed internally by the organization, but also driven by the market (Suresh \& Krishnaraj, 2015). Retaining talented and loyal employees is considered one of the major challenges faced by private and public organizations in the Gulf Cooperation Council (GCC) countries in general, and in the UAE in particular (Suliman \& Obaidli, 2011). This makes it clear why the government has taken an interest in enhancing employee retention rates by promoting the establishment of a culture of excellence (Kassem et al., 2016).

While this paper takes organizational culture as a critical dimension, it also integrates other variables that may affect retention of talent in an organization. Moreover, the paper takes into consideration the excellence framework promoted by the UAE government to improve the country's economy and competitiveness (Kassem et al., 2016).

\subsection{Knowledge sharing}

Nowadays, knowledge management has become increasingly popular (Suresh, 2014). Previous researches (Jabeen \& Al Dari, 2020; Nuaimi \& Jabeen, 2020) highlights that knowledge sharing is a major aspect of knowledge management, and knowledge sharing also constitutes an important cause of employee retention that feeds directly into a positive attitude toward the workplace. Hence, it is also used as strategic tool by executives to keep their team motivated (Surbakti \& Ta'a, 2016). The main purpose behind sharing knowledge is to spread decision-making for effective knowledge management and personnel retention, since employees will stay at firms where their views and suggestions are accorded importance (Surbakti \& Ta’a, 2016). 
Knowledge sharing covers communication strategies, policies, and techniques intended for sustaining organizational competitiveness. All those practices strive to bring into being an optimal environment for realizing efficiency enhancement, modernization, and teamwork (Iqbal \& Mahmood, 2012). Knowledge sharing nurtures the organizational capabilities necessary for creating economic value, sustaining a competitive advantage, and achieving superior organizational performance (Keelson, 2014; Morris, Hammond, \& Snell, 2014). Conversely, lack of knowledge sharing among employees and management causes frustration leading to confusion and inefficiencies (Laddha et al., 2012). A lot of firm talent can be lost if employees perceive themselves to be in dead-end positions (Surbakti \& Ta'a, 2016).

For this reason, we have chosen to focus in this paper on certain practices that impact knowledge and capabilities in the organization, in order to rank those practices based on their impact on the model variables. These practices are called sub-variables and, in connection to knowledge sharing, we selected the following sub-variables: organizational culture, team building, formal gathering, and informal gathering.

\subsection{Involvement and empowerment}

According to EFQM (2013), the pursuit of organizational excellence recommends certain practices for aligning, involving, and empowering the workforce. These include: harmonizing personal and team objectives, and empowering people to realize their full potential in a spirit of true partnership.

Studies have confirmed that employee development results in higher engagement. Specifically, employee development is aided by employee empowerment, alignment, and involvement in the workplace (Muthuveloo et al. 2013). Findings from the literature suggest that organizational performance is improved when employee engagement is increased, and when staff are empowered and involved in their working environment: both are essential for sustaining high achievement in customer satisfaction, employee retention, and organizational performance (Hanif \& Yunfei, 2013; Brunges, 2014).

According to Abd-El-Salam, Shawky, El-Nahas, and Nawar (2013), continuing interpersonal relationships nurture mutual reliance between employers and their employees and, in turn, catalyze a process whereby employees develop the competence to take charge of their own development and address the problems facing them. In general, the term 'empower' means to give power and energize, or enable. The study just mentioned also adds that employee empowerment is critically important in today's competitive environment, since it can give a company a sustained advantage. These findings suggest that empowering employees is another valuable option to increase their job satisfaction. Furthermore, enabling a high degree of empowerment means that employees may come to possess the knowledge, skills, attitudes, abilities, and behavior to sustain a more creative and rational problem-solving approach, but also to enrich the company's goal-setting (Iqbal \& Hashmi, 2015).

Empowerment has a significant effect on the retention of employees, and it is enhanced by proper training - which of its own is also beneficial to employee retention (Deo, 2014). Brunges (2014) reports that hospitals perform better over time in virtually every measurable category when employees are engaged with what they are doing and committed to their jobs. Psychological empowerment makes individuals engage with decision-making processes on organizational 
matters by equipping them with a sense of control and independence (Iqbal \& Hashmi, 2015; Parwez, 2013; Krishnan et al., 2013). Organizational culture and knowledge sharing impact significantly employee engagement, and organizations will have a higher rate of retention in public sector in the UAE (Al Mehrzi \& Singh, 2016). These findings from the literature compose a picture where perceived organizational support yields considerable benefits, not least on employee retention. On this basis, the sub-criteria for empowerment and involvement, which we have chosen to assess in this research, are the following: delegation, engagement, and alignment.

\subsection{Effective communication}

Organizations need to understand the communication needs of their employees and use appropriate strategies and tools to keep dialogue alive. In addition, they need to define the communicative skills, competencies, and their requisite level of performance for achieving their mission and strategic goals. Effective communication also captures some features of organizational culture specifically supported by the framework of organizational excellence (EFQM, 2013), in order to nurture a culture that continuously seeks to improve the effectiveness of collaboration and teamwork.

Communication can be further enhanced by the adoption of apposite technology (Surbakti \& Ta'a, 2016; Laddha et al., 2012). Massive development in information technology and communication makes it possible to rely on Business Intelligence (BI) applications to scrutinize business processes, market presence, competition, customer control, and retention. In a transparent organization, employees may get a sense of achievement, and of belonging to a healthy work environment.

Communicating a brand image and its distinctive features is also very important to check the risk of high turnover intentions amidst employees (Kashyap \& Rangnekar, 2014; Singh et al., 2012). In an increasingly competitive environment, employer branding helps recruit and retain the best human talent (Kashyap \& Rangnekar, 2014). Further, Ewing, Pitt, and De Bussy (2002, p. 12) outline it as follows: 'Employment branding is concerned with building an image in the minds of the potential labour market that the company, above all others, is a "great place to work".

Muthuveloo et al. (2013) conclude in their study that communication is directly related to employee engagement. The clearer a development plan, objective and vision are laid out, the more transparent the working environment will be, and this will in turn result in higher employee commitment. According to Kasekende, Byarugaba, and Nakate (2014) more attention also needs to be paid to organizational service orientation and employee satisfaction to improve retention rates. The quality of work life, which means the quality of relationship between employees and their managers, had proven to have a positive impact on reducing the turnover rate of Emirati women working in public sectors (Jabeen, Friesen, \& Ghoudi, 2018).

Under the criterion of effective communication, the foregoing review of literature suggests the inclusion of the following sub-criteria to complement our model: dual (interpersonal) communication; transparency and clarity; and well-defined roles and responsibilities. Instead, employer branding is considered as part of the reward and recognition factor discussed in the next section. 


\subsection{Reward and recognition}

The framework for excellence in organizational performance encourages practices of employee reward and recognition, which motivate people to get involved in improvement and innovation efforts and recognize their work and achievements. The delivery of employee benefits through transparent strategies and policies is another practice recommended in the framework for organizational excellence. The same framework also recommends the promotion of a culture of mutual support, recognition, and care between individuals and teams (EFQM, 2013).

Many studies of employee turnover have identified, amongst factors consistently linked to turnover, precisely the issue of reward and recognition. Those studies indicate that there is a clear linkage between reward and recognition, on the one hand, and employee motivation and willingness to stay, on the other (Krishnan et al., 2013; Mutsuddi, 2016).

Oladapo (2014) has suggested that job security, compensation, and opportunities for career advancement might not hold predictive value over employee retention rate. Still, effective management of employee performance, coupled with a robust reward and recognition structure, contributes to higher employee productivity, engagement, and consequentially higher levels of employee retention, according to Krishnan et al. (2013). Muthuveloo et al. (2013) further add that reward and recognition policies are direct contributors to the level of employee engagement. The same study suggests that an improved regime of extended employee care will also lead to higher employee engagement. The cited researchers conclude that employee development is the most significant contributing factor to employee engagement. The list of contributing factors also includes organizational culture, rewards and recognition, and work-life balance, according to Arora (2012). In the UAE, it was found that there is positive relationships between compensation and employee retention in public healthcare sector (BaniMelhem, Elanain, \& Hussain, 2019). On this basis, our paper evaluates the reward and recognition factor alongside several sub-variables, such as: financial and non-financial recognition, as well as branding, which is treated under the 'reward and recognition' rubric on the basis of a suggestion by Kashyap and Rangnekar (2014).

\subsection{Sustainable practices}

It is very difficult for some organizations to sustain their business for a long-time due to planning problems, lack of competent staff, or lack of business acumen (Al Hammadi \& Hussain, 2019). Sustainability is defined as 'meeting people's present needs without comprising the needs of the future generations to meet their own needs' (Bruntdland, 1987, p. 41). HRM practices may nurture distinctive competencies as a source of sustained competitive advantage. In so doing, they may clearly influence in a positive manner the company's economic position within the environment in which it operates (Barney, 1991). Many organizations now realize that sustainability can strengthen their competitive advantage and guide innovation in their processes, products, services, markets, and business models (Hubbard, 2009). Current research on sustainability scrutinizes organizational performance through the lens of the triple bottom line (environmental, social, and economic), with specific reference to manufacturing organizations (Hussain, Malik, \& Al Neyadi, 2016; Al-Aomar \& Hussain, 2017). However, the investigation of sustainable organizational performance in the service industry in general, and healthcare in particular, still remains an underexplored research domain (Hubbard, 2009; Hussain et al., 2016). This paper attempts to fill this gap by assessing the impact of sustainable practices on employee retention. 
Nowadays, the Human Resources (HR) department is the main connecting link between top management and all other divisions, when it comes to routine tasks like circulating policies, standards, and legal precautions. HR also acts as a go-between for other kinds of organizational information, like the development of strategies and best practices to strengthen critical decisionmaking skills (Jabbour, Santos, \& Nagano, 2010). In connection to this, Tobey and Benson (2009) suggest there is strategic value in integrating HRM activities within an appropriate set of environmental factors. Therefore, our model assesses how organizational guidelines and empowerment, work ethics, and social responsibility might influence employee retention. It also attempts to rank which, among, those factors, most influence sustainable practices.

\subsection{Career development and succession planning}

Studies show that when a company takes time to work with its employees on their career, it elicits a sense of dependency and loyalty from the employee. Employees tend to remain at companies that show a vested interest in their success (Krishnan et al., 2013). These practices include training, participation, results-oriented appraisals, and internal career opportunities (Akhtar, Ding, \& Ge, 2008). In a cross-cultural study of managerial attitudes about HRM practices, Jennings, Cyr, and Moore (1995) found that training and development is perceived as the most important strategic HRM practice by managers. Employee training is also seen as a critical and effective tool to ensure product and service quality and standards. These considerations clearly show that training helps improve the career development of employees and enhances their capabilities, thereby allowing the replacement of foreign experts (Wenmi Net, 2007; Beamish, 1993). In the UAE, Khan (2018) has found that training can impact the employee's retention in private sector. Furthermore, Al Suwaidi, Jabeen, Stachowicz-Stanusch, and Webb (2020) affirmed that succession planning is important for organizational growth and business sustainability. Barney's (1991) resource-based theory of the firm has often been used to support the contention that strategic HRM practices may create distinctive competencies as a source of sustained competitive advantage. Indeed, HRM practices strengthen the competitive position of a company, and the community surrounding it. This reverberates on the sustainability of the firm's performance and sets in motion a sustainable process. It also has a positive impact on employee engagement, organizational performance, and employee retention. To assess the impact on employee retention of the career development practices pursued through HRM, our paper focuses on the following sub-criteria: coaching and mentoring, career path, and capacity building.

\section{METHODOLOGY}

\subsection{Methodology}

Analytic Hierarchy Process (AHP) is the methodology we have used in this paper to collect data and to assess the relative weight of multiple criteria or of multiple options against given criteria (Figure 1). In this study, the AHP model has been implemented using 6 criteria and 19 sub-criteria based on the literature. Data were collected by interviewing 18 employees, who were arranged into three groups: administrators, medical staff, and medical researchers from UAE-based public healthcare units. The data so collected were interpreted and a priority vector was assigned to each criterion and sub-criterion to rank the various factors affecting talent retention. 


\subsection{AHP overview}

AHP is a methodology for judging and selecting which elements or concepts have a greater influence on a predetermined objective. It is used to evaluate accurately the impact of a certain criterion against specified goals. This method can be helpful for segmenting a decision process into an order of priority. The ensuing hierarchy helps with decision-making, when decision-making demands choosing an option amidst alternatives. AHP operates through a process of pair-wise comparisons at each level of the hierarchy. A matrix can then be developed, in which the entries indicate the strength with which one element dominates over another, against a given criterion. Therefore, AHP can be conceptualized as a method of measurement through pair-wise comparison, which leverages the judgment of experts to derive priority scales. It helps move from intangible assessments to tangibles judgments. Intangible assessments are measured in relative terms. Comparisons are made using a scale of absolute judgment that represents by how much one element dominates over another, with respect to a given attribute. The main concern of AHP is to deal with inconsistencies arising in the course of judgment, in order to improve its coherence (Vinodh \& Joy, 2012). Figure 1 presents, in outline form, the AHP method employed in this research.

Figure 1: Outlines the AHP method used in this research (Saaty, 2012)

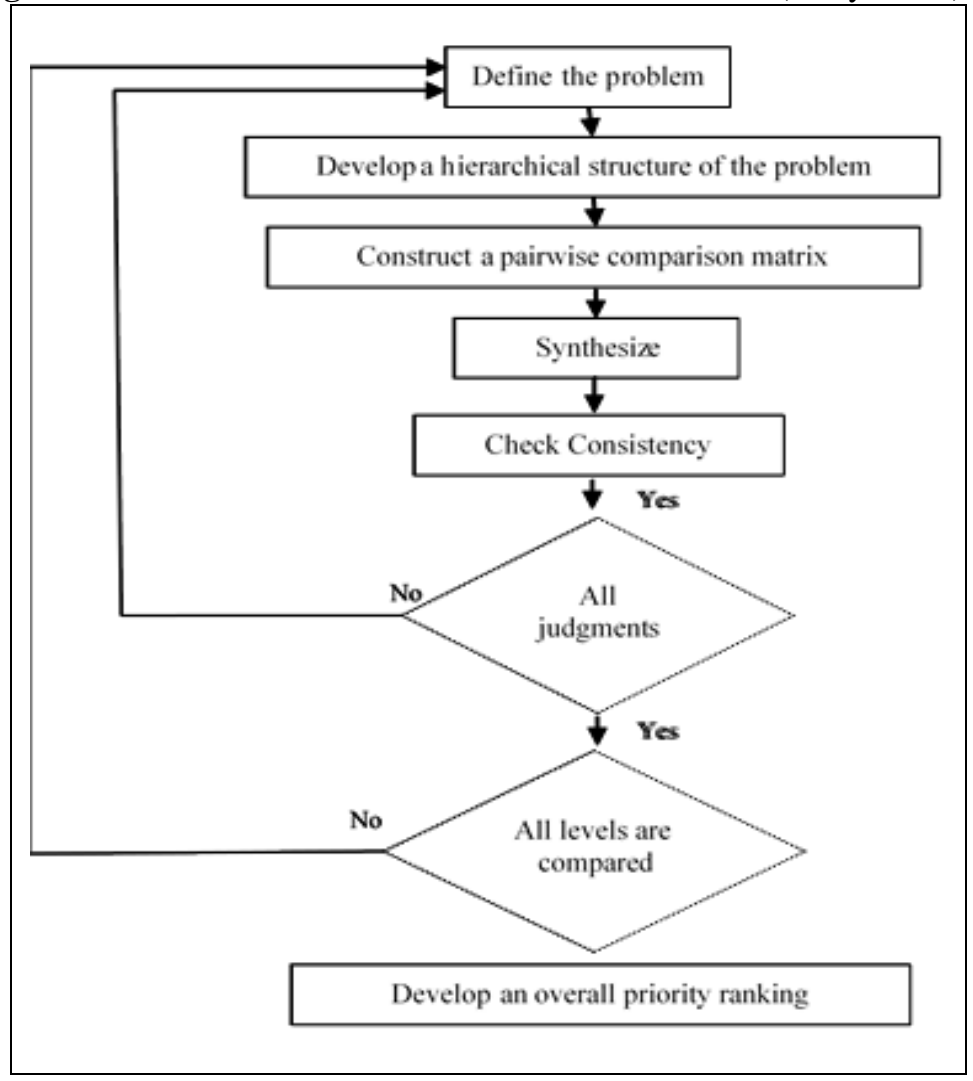


The AHP method of analyzing rational and irrational evaluations according to their level of importance for decision-making was developed by Saaty (1980). AHP helps to formulate and simulate the course of human decision-making in multi-criteria evaluation procedures. In addition, it affords an effective method of analyzing the strategic behavior of a company in the face of a complex problem, by disaggregating the problem hierarchically. In other words, it simulates a structured approach by the decision-maker, allowing him/her to deal with a given problem by breaking it down into a multi-level hierarchy. The number of levels in the hierarchy is what defines the complexity of the problem. Ishizaka, Pearman, and Nemeri (2012) also highlighted the usefulness of AHP's multi-level hierarchical structure - consisting of objectives, criteria and alternatives - for improving consistency, and for comparing the relative performance of an organization.

There are a number of factors contributing to the sustainability of the AHP, including AHP's ease of use and flexibility against a wide range of unstructured problems. Furthermore, AHP implements a deductive approach for solving complex problems stemming from the interdependencies of the system elements. It also reflects a natural tendency in the human mind to sort elements of a system into different levels and group-like clusters (Hussain, Ajmal, Khan, \& Saber, 2015). Above all, the AHP was chosen in our research as the most efficient way to scale and measure intangible assessments, because it afforded a method to draw upon the experience of practitioners for the identification and ranking of process improvement opportunities in the health sector.

Recently, there has been a renewed interest in this method as an approach to address complex realworld and multi-criteria decision-making problems (Drake, Myung Lee, \& Hussain, 2013; Ishizaka et al., 2012). Finally, AHP has also been used in other contexts to select between alternatives (decision-making) or to generate a priority ranking (Badurdeen, Wijekoon, \& Marksberry, 2011). Over the years, it has become one of the most widely used tools for decision support for researchers and decision-makers (Subramanian \& Ramanathan, 2012).

AHP also plays a significant role in healthcare and medical decision-making. Liberatore and Nydick (2008) report that over 50 papers implemented AHP in healthcare applications ranging from diagnosis, patient participation in medical decision-making, evaluation and selection of medical treatments, organ transplant eligibility, allocation decisions, and project evaluation and selection. Following this emerging stream of work, our study implements an AHP framework to leverage the experience of healthcare staff in order to identify, prioritize, and select factors that influence employee retention in the healthcare sector.

\section{AHP MODEL AND ANALYSIS}

\subsection{AHP model}

The first step in implementing the AHP model is identification of the problem (Figure 1). The objective of the research is to identify, prioritize, and select significant talent retention factors to aid managerial decision-making at public hospitals in Abu Dhabi. Our research design fleshes out the goal of talent retention through multi-criteria attributes. Figure 2 illustrates the hierarchy of the AHP framework, as we have adapted it to model decision-making in the domain of talent retention 
practices, from the perspective of the healthcare industry. Level 2 contains the multiple sub-criteria included under the six main criteria for talent retention: each main (parent) criterion comprises of several sub-criteria (child) that flesh out the parent attribute, for an aggregate total of 19 subcriteria.

Figure 2: AHP model for retaining talent in healthcare (HC) organizations

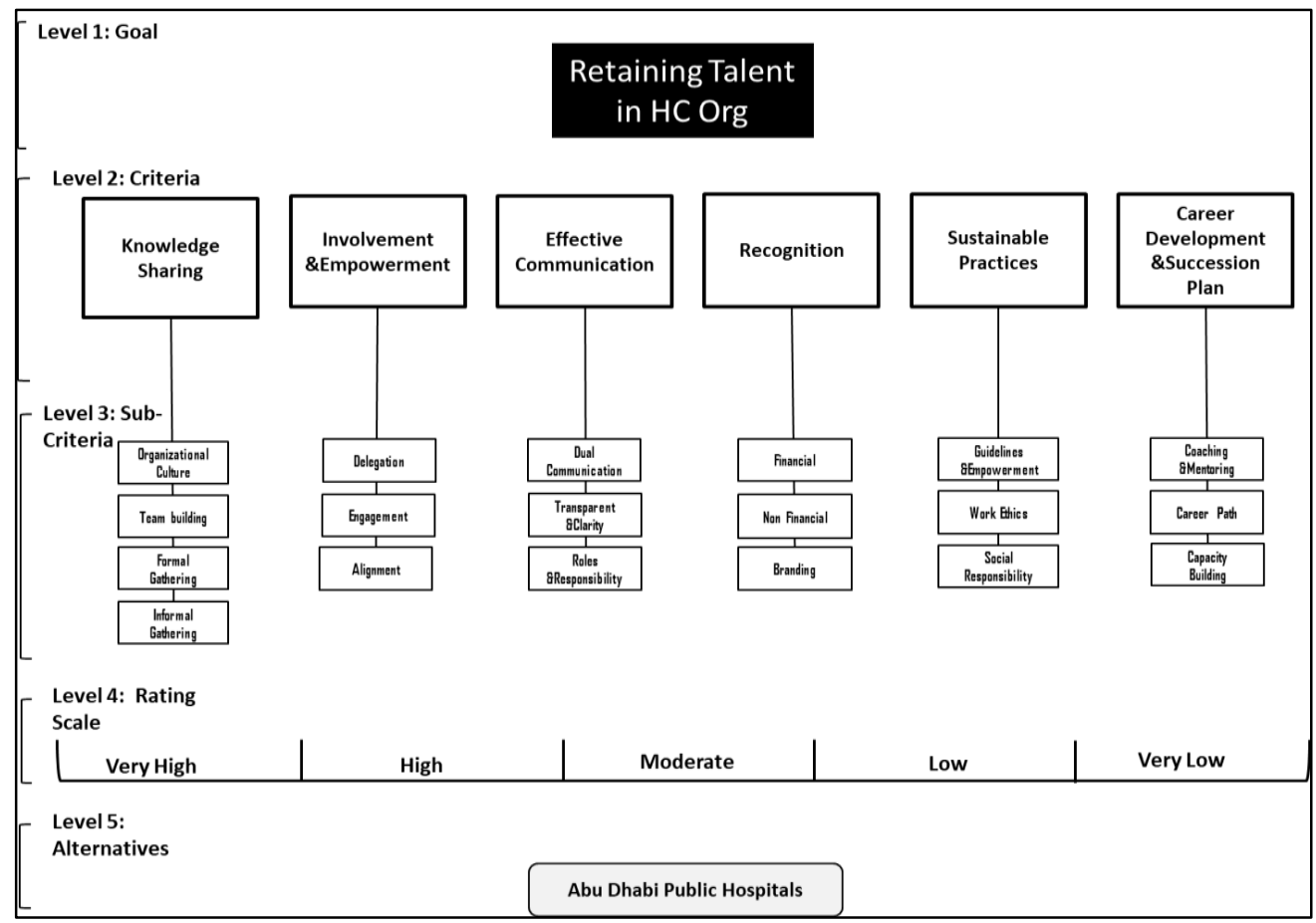

After designing this AHP hierarchy model, data was collected from Human Resource professionals at Abu Dhabi healthcare institutions. Following the recommendations by Saaty (1980), the questionnaire was designed on a nine-point scale (Table 2). The interviewed 18 managers of healthcare institutions responded to the questionnaire. We ascertained that those respondents had sufficient experience and conceptual knowledge to influence talent retention practices in the healthcare industry. The attested knowledge and high-ranking position of each of the respondents increase the robustness and validity of our research framework. 
Table 1. Coding of criteria and sub-criteria

\begin{tabular}{|c|c|c|c|c|c|}
\hline & Criteria & Sub-c & & Priority & References \\
\hline \multirow[t]{4}{*}{ KS } & \multirow{4}{*}{$\begin{array}{l}\text { Knowledge } \\
\text { Sharing (KS) }\end{array}$} & $\mathrm{OC}$ & Org Culture & KS1 & \multirow{4}{*}{$\begin{array}{l}\text { Suresh (2014), Morris et al. } \\
\text { (2014), Kashyap and } \\
\text { Rangnekar (2014). }\end{array}$} \\
\hline & & $\mathrm{TB}$ & Team Build & $\mathrm{KS} 2$ & \\
\hline & & FG & Formal Gathering & $\mathrm{KS} 3$ & \\
\hline & & InFG & $\begin{array}{l}\text { Informal } \\
\text { Gathering }\end{array}$ & $\mathrm{KS} 4$ & \\
\hline \multirow[t]{3}{*}{$\mathrm{IE}$} & \multirow{3}{*}{$\begin{array}{l}\text { Involvement and } \\
\text { Empowerment } \\
\text { (IE) }\end{array}$} & $\mathrm{D}$ & Delegation & IE1 & \multirow{3}{*}{$\begin{array}{l}\text { Brunges (2014), Morris et } \\
\text { al. (2014), Abd-El-Salam } \\
\text { et al. (2013), Iqbal and } \\
\text { Hashmi (2015), } \\
\text { Muthuveloo et al. (2013), } \\
\text { Deo (2014). }\end{array}$} \\
\hline & & $\mathrm{Eg}$ & Engagement & IE2 & \\
\hline & & $\mathrm{A}$ & Alignment & IE3 & \\
\hline \multirow[t]{3}{*}{$\mathrm{EC}$} & \multirow{3}{*}{$\begin{array}{l}\text { Effective } \\
\text { Communication } \\
\text { (EC) }\end{array}$} & $\mathrm{DC}$ & $\begin{array}{l}\text { Dual } \\
\text { Communication }\end{array}$ & $\mathrm{EC} 1$ & \multirow{3}{*}{$\begin{array}{l}\text { Singh et al. (2012), James } \\
\text { and Mathew (2012), } \\
\text { Muthuveloo et al. (2013), } \\
\text { Kashyap and Rangnekar } \\
(2014) \text {. }\end{array}$} \\
\hline & & $\mathrm{TC}$ & $\begin{array}{l}\text { Transparency and } \\
\text { Clarity }\end{array}$ & $\mathrm{EC} 2$ & \\
\hline & & $\mathrm{RR}$ & $\begin{array}{l}\text { Roles and } \\
\text { Responsibilities }\end{array}$ & EC3 & \\
\hline \multirow[t]{3}{*}{$\bar{R}$} & \multirow{3}{*}{$\begin{array}{l}\text { Rewards and } \\
\text { Recognition (R) }\end{array}$} & $F$ & Financial & $\mathrm{R} 1$ & \multirow{3}{*}{$\begin{array}{l}\text { Krishnan et al. (2013), } \\
\text { Mutsuddi (2016), Oladapo } \\
\text { (2014), Muthuveloo et al. } \\
(2013) \text {, Arora (2012). }\end{array}$} \\
\hline & & $\mathrm{NF}$ & Non-Financial & $\mathrm{R} 2$ & \\
\hline & & $\mathrm{B}$ & Branding & $\mathrm{R} 3$ & \\
\hline \multirow[t]{3}{*}{ SP } & \multirow[t]{3}{*}{$\begin{array}{l}\text { Sustainable } \\
\text { Practices (SP) }\end{array}$} & GE & $\begin{array}{l}\text { Guidelines and } \\
\text { Empowerment }\end{array}$ & SP1 & \multirow{3}{*}{$\begin{array}{l}\text { Bruntdland } \\
\text { Hubbard (2009), Hussain et } \\
\text { al. (2016), Al-Aomar \& } \\
\text { Hussain } \\
\text { Hammadi } \text { (2017), Al } \\
\text { (2019). }\end{array}$} \\
\hline & & WE & Work Ethics & SP2 & \\
\hline & & $\mathrm{SR}$ & $\begin{array}{l}\text { Social } \\
\text { Responsibility }\end{array}$ & SP3 & \\
\hline \multirow[t]{3}{*}{$\mathrm{CrP}$} & \multirow{3}{*}{$\begin{array}{l}\text { Career } \\
\text { Development and } \\
\text { Succession } \\
\text { Planning }(\mathrm{CrP})\end{array}$} & $\mathrm{CM}$ & $\begin{array}{l}\text { Coaching and } \\
\text { Mentoring }\end{array}$ & CrP1 & \multirow{3}{*}{$\begin{array}{l}\text { Akhtar et al. (2008), } \\
\text { Wenmi Net (2007), Barney } \\
\text { (1991), Beamish (1993). }\end{array}$} \\
\hline & & $\mathrm{CP}$ & Career Path & $\mathrm{CrP} 2$ & \\
\hline & & $\mathrm{CB}$ & $\begin{array}{l}\text { Capacity } \\
\text { Building }\end{array}$ & $\mathrm{CrP} 3$ & \\
\hline
\end{tabular}

Table 2. Scale for AHP preferences

\begin{tabular}{lll}
\hline \hline $\begin{array}{l}\text { Intensity of } \\
\text { importance }\end{array}$ & Definition & Explanation \\
\hline 1 & Equal importance & Moderate importance \\
3 & Strong importance & $\begin{array}{l}\text { Two criteria contribute equally to the objective } \\
\text { Judgment slightly in favor of one over the other } \\
\text { Judgment strongly in favor of one over the other }\end{array}$ \\
7 & Very strong importance & $\begin{array}{l}\text { A criterion is strongly favored and its dominance is } \\
\text { demonstrated in practice }\end{array}$ \\
9 & Absolute importance & $\begin{array}{l}\text { Importance of one criterion over the other affirmed on } \\
\text { the highest possible order } \\
\text { These intermediate values represent compromise } \\
\text { between the priorities listed above }\end{array}$ \\
\hline \hline
\end{tabular}


Target respondents possessed knowledge and experience of human resource management practices in healthcare institutions. According to prior researchers (Cheng \& Li, 2001; Mehrajunnisa \& Jabeen, 2020), even a small sample size is acceptable when using AHP methodology. Comparing the relative importance of two competing needs at a specific point in time, as is the case in the AHP, places less emphasis on how large the size of the survey ought to be, in order to be acceptable. In the AHP model, comparisons are called judgments. What this entails is that participants are asked to compare only two items at a time, rather than a list of 20 or more. Hence, logical thinking and past experience are the main resources needed when judgments are issued, in order to make paired comparisons. Pair-wise comparisons generate more information and, therefore, improve judgment consistency (Saaty, 2012). On this basis, even a sample size of 3 experts/respondents can be deemed acceptable for our research (Saaty, 2012; Drake et al., 2013). In order to derive from individual responses, the consensus pair-wise comparison matrices for the entire group, the geometric mean approach was preferred over arithmetic mean when combining individual pairwise comparisons, as recommended by Saaty (2012).

The third step, as shown in Figure 1, involves establishing pair-wise comparisons between the different criteria of the model. Saaty (2012) suggests using a nine-point scale (Table 2) for this purpose. For example, if an evaluator feels that 'involvement and empowerment' is equal, or moderately preferred, to 'knowledge sharing', then the former receives a rating of ' 2 ' and the latter of ' $1 / 2$ '. Also, if one participant selects the career development as strongly favoured over a recognition, then the first one takes rating of 5 and the second one takes 1/5 and so on. To check for consistency, a consistency index (CI) has been applied. Saaty (1980) defines consistency as follows- see equation (1):

$$
C I=\frac{\lambda_{\max }-n}{n-1}
$$

Where $\lambda \max$ is the maximum eigenvalue of the matrix of importance ratios, and $n$ is the number of factors. A consistency ratio (CR) is used to assess whether a matrix is sufficiently consistent or not. This is the ratio of the CI to the random index (RI), which is the CI of a randomly generated matrix of comparisons-see equation (2):

$$
C R=\frac{C I}{C R}
$$

Random pair-wise comparisons have been simulated to produce average random indices for different-sized matrices. The values for the RI are given in Table 3. According to Saaty (1980), if the value of the CR is smaller than, or equal to, 0.10 , then the inconsistency is acceptable.

Table 3. Random Index

\begin{tabular}{lllllllllll}
\hline \hline $\mathbf{n}$ & 1 & 2 & 3 & 4 & 5 & 6 & 7 & 8 & 9 & 10 \\
\hline RI & 0.00 & 0.00 & 0.58 & 0.90 & 1.12 & 1.24 & 1.32 & 1.41 & 1.45 & 1.48 \\
\hline \hline
\end{tabular}

Table 4 illustrates the pair-wise comparisons between the six main criteria, by means of a geometrical analysis. The final column in Table 4 defines the relative priority of criteria by computing 'priority vectors'. Saaty (1990) introduces a 'consistency principle' for calculating priority vectors. The consistency principle can be stated formally as follows: 


$$
\mathrm{a}_{\mathrm{ik}}=\mathrm{a}_{\mathrm{ij}} * \mathrm{a}_{\mathrm{jk}}
$$

This applies to the special case of a consistency matrix formed by elements $a_{i k}=\frac{w_{i}}{w_{k}}$, where $w_{i}$ and $w_{j}$ are the elements of the priority weight vector corresponding to criteria $\mathrm{i}$ and $\mathrm{j}$.

\subsection{Analysis}

Our study outcomes have been generated from three groups of respondents: administrators, medical staff, and medical researchers. We approached the corporate HR department stating exactly the objective of this study and requesting them to share with us their criteria for classification of the workforce in the healthcare sector. Their classification distinguished between clinical and non-clinical (administration) staff. Subsequently, we decided to add the point of view of medical researchers, who might combine both the above role classifications, since this might help us ascertain whether researchers would yield a different outcome to the other two groups.

Table 4 represents the pair-wise comparisons of the main criteria of the study for each of the three groups of respondents. It reveals that recognition is considered the most important factor by respondents in the administrators group, with a priority weight of $25 \%$, followed by sustainable practices and knowledge sharing, which have an equal priority of $21 \%$. Involvement and empowerment, effective communication, and career development and succession planning were ranked third, fourth and fifth, respectively. It is pertinent to note here that participants' responses fulfill the acceptable CR requirement, yielding CR rates of 0.05 and 0.04 , both of which fall within the acceptable threshold of consistency of 0.10 .

The highest ranked criterion for medical staff is career development and succession planning with a weight of $34 \%$. This is followed by sustainable practices at $22 \%$, and effective communication at $16 \%$. In addition, recognition, involvement and empowerment, and knowledge sharing are weighted $14 \%, 11 \%$ and $3 \%$, respectively. The criterion with highest priority for medical researchers is shown to be sustainable practices at $39 \%$, followed by career development and succession planning at $26 \%$, and recognition at $18 \%$. Effective communication, involvement and empowerment, and knowledge sharing attract weights of $8 \%, 6 \%$ and $3 \%$, respectively, with a consistency rate of $0.04<0.10$. The two most important criteria for researchers and medical staff are similar. These groups also agree on the least important criterion, namely knowledge sharing. This might be a consequence of the focus on individual learning in the work environment of many clinical staff and researchers. 
Table 4: Geometric means of pair-wise comparisons of the main criteria based on responses by administrators, medical staff, and medical researchers

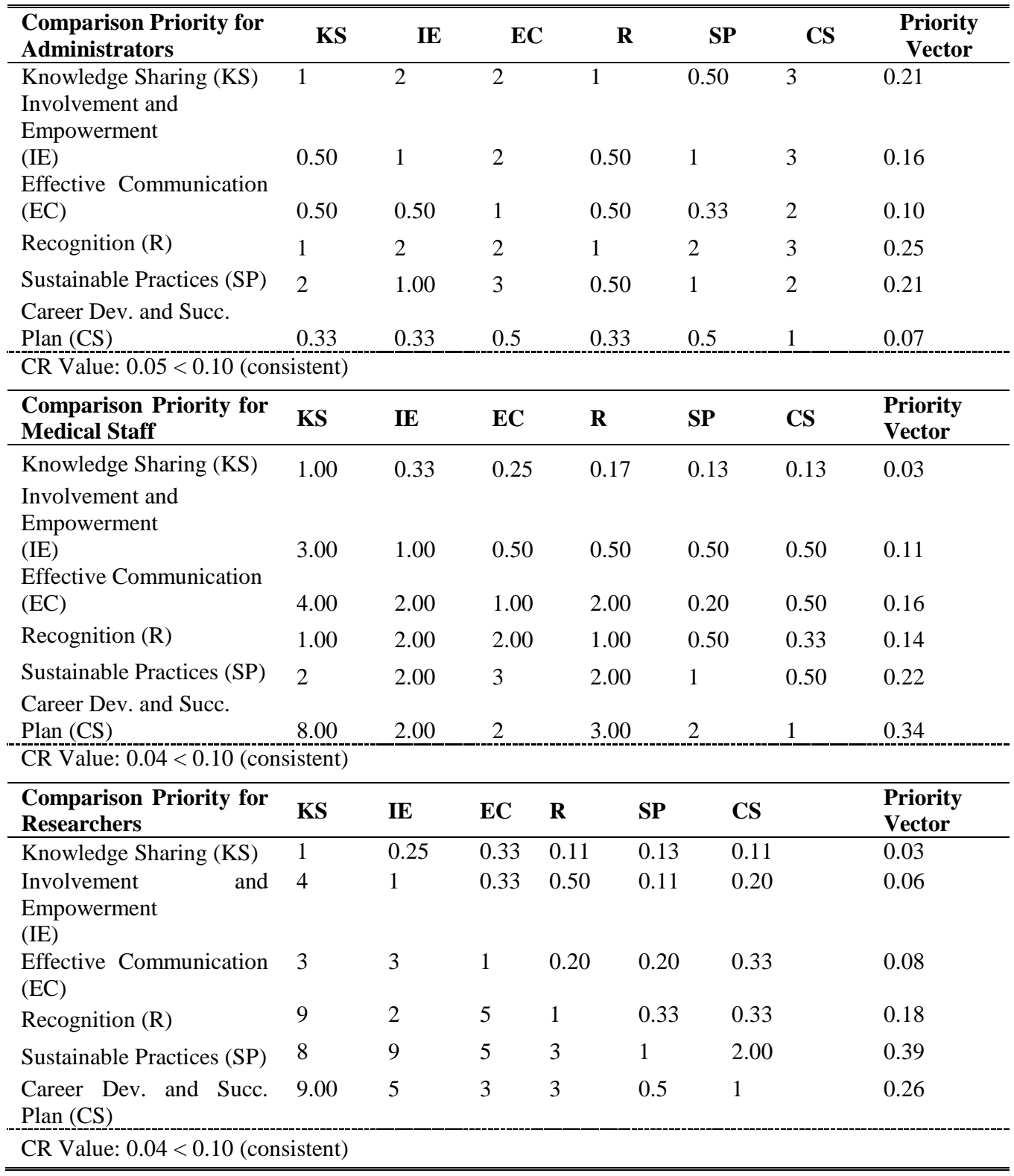

To gain deeper insight into the priorities reported above, an additional pair-wise comparison among sub-criteria within each parent criterion has also been carried out, based on the responses from each of the three groups. The outcomes of this additional level of comparison are presented in Tables 5 to 10. Table 1 already shows how each parent criterion was further divided into child subcriteria. The parent criterion 'knowledge sharing' consisted of four sub-criteria: organizational 
culture (OC), team building (TB), formal gathering (FG), and informal gathering (InFG). Table 5 displays the priority listing originating from the pair-wise comparisons of the four sub-criteria for knowledge sharing, for each of the three respondent groups. In group 1 (administrative staff), formal gathering shows the highest weight of $42 \%$, whereas team building has the lowest at $12 \%$. The remaining two sub-criteria, namely, organizational culture and formal gathering, were ranked equally at $23 \%$, with a consistency rate $(\mathrm{CR})$ of $0.8<0.10$, which makes those findings acceptable.

Respondents in the medical staff group confirmed the importance of team building for medical roles in treating cases. This group's responses recorded the highest weight for team building at 63 $\%$, followed by organizational culture at $25 \%$. Finally, formal and informal gathering rank almost identically at 6 and 7\%, respectively. The consistency rate of responses is acceptable at $0.07<$ 0.10 .

Similarly, the nature of the work environment in medical research explains the high consideration for organizational culture $(58 \%)$, followed by team building and informal gathering with similar weights of $19 \%$ and $14 \%$, respectively. The least important variable is concerned with formal gathering, with a weight of just $9 \%$. This might be because medical researchers do not usually rely on formal meetings to share or generate knowledge. The consistency rate of this set of responses is very robust with a $\mathrm{CR}$ rate of $0.02<0.10$.

Table 5: Geometric means of pair-wise comparisons of sub-criteria (Knowledge Sharing) for administrators, medical staff, and medical researchers

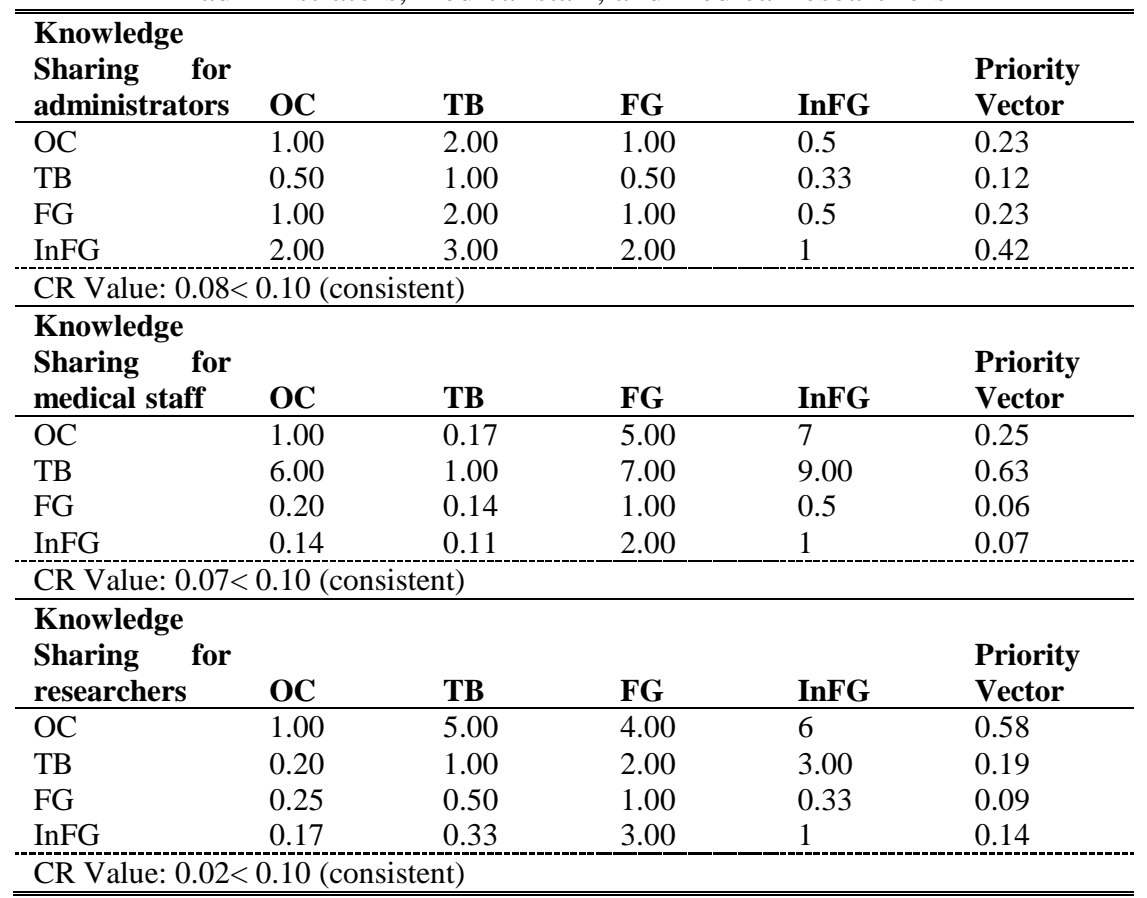


Moving on to another parent criterion, involvement and empowerment, this has been broken down into three sub-criteria, namely: delegation (D), engagement (E), and alignment (A) (Table 6). For administrators, delegation carries the highest weight of $59 \%$. This is followed by engagement $(25 \%)$ and alignment (16\%). The same ranking also describes the preferences of medical researchers: delegation is the highest ranked, followed by engagement and then by alignment, with vector weights of $78 \%, 15 \%$, and $7 \%$, respectively. The CR for both sets of responses is less than 0.10 .

On the other hand, the highest priority for medical staff was engagement, followed by alignment, with weights of $56 \%$ and $36 \%$, respectively. This confirms our earlier hypothesis concerning the importance of team building for this professional group. Finally, delegation only gathered a weight of $8 \%$, likely due to the nature of medical roles and their attendant responsibilities, which need to be very precise in order to complement one another's roles as part of a team. The CR for medical staff responses is acceptable with a rate of $0.05<0.10$.

Table 6: Geometric means of pair-wise comparisons of sub-criteria (Involvement and Empowerment) for administrators, medical staff, and medical researchers

\begin{tabular}{|c|c|c|c|c|}
\hline $\begin{array}{ll}\begin{array}{l}\text { Involvement } \\
\text { Empowerment } \\
\text { administrators }\end{array} & \begin{array}{l}\text { and } \\
\text { For }\end{array} \\
\end{array}$ & D & Eg & $\mathbf{A}$ & $\begin{array}{l}\text { Priority } \\
\text { Vector }\end{array}$ \\
\hline $\mathrm{D}$ & 1 & 3 & 3 & 0.59 \\
\hline $\mathrm{Eg}$ & 0.33 & 1 & 2 & 0.25 \\
\hline $\mathrm{A}$ & 0.33 & 0.5 & 1 & 0.16 \\
\hline \multicolumn{5}{|l|}{ CR Value: $0.05<0.10$ (consistent) } \\
\hline $\begin{array}{l}\text { Involvement } \quad \text { and } \\
\text { Empowerment for medical staff }\end{array}$ & D & Eg & $\mathbf{A}$ & $\begin{array}{l}\text { Priority } \\
\text { Vector }\end{array}$ \\
\hline $\mathrm{D}$ & 1 & 0.17 & 0.17 & 0.08 \\
\hline $\mathrm{Eg}$ & 6.00 & 1 & 2 & 0.56 \\
\hline A & 6.00 & 0.5 & 1 & 0.36 \\
\hline \multicolumn{5}{|l|}{ CR Value: $0.05<0.10$ (consistent) } \\
\hline $\begin{array}{l}\text { Involvement and } \\
\text { Empowerment for researchers }\end{array}$ & D & Eg & $\mathbf{A}$ & $\begin{array}{l}\text { Priority } \\
\text { Vector }\end{array}$ \\
\hline $\mathrm{D}$ & 1 & 7 & 9 & 0.78 \\
\hline $\mathrm{Eg}$ & 0.14 & 1 & 3 & 0.15 \\
\hline A & 0.11 & 0.33 & 1 & 0.07 \\
\hline
\end{tabular}

Concerning the parent criterion of effective communication (Table 7), respondents from the administrator group rated dual (interpersonal) communication (DC) as the most important variable at $57 \%$. This was followed by transparency and clarity (TC), and roles and responsibilities (RR) at $29 \%$ and $14 \%$, respectively. The CR is acceptable at $0.00<0.10$.

Table 7 also displays identical rankings for the responses of medical staff and medical researchers. The sequence in both cases is RR (57\%), TC (36\%), and finally DC (7\%). Responses from both groups are consistent with a CR value of less than 0.10 . 
Table 7: Geometric means of pair-wise comparisons of sub-criteria (Effective Communication) for administrators, medical staff, and medical researchers

\begin{tabular}{lllll}
\hline \hline $\begin{array}{l}\text { Effective Communication for } \\
\text { administrators }\end{array}$ & DC & TC & RR & $\begin{array}{l}\text { Priority } \\
\text { Vector }\end{array}$ \\
\hline DC & 1 & 2 & 4.00 & 0.57 \\
TC & 0.50 & 1.00 & 2.00 & 0.29 \\
RR & 0.25 & 0.50 & 1.00 & 0.14 \\
\hline CR Value: $0.00<0.10$ (consistent) & & & \\
\hline Effective Communication for & & & & Priority \\
medical staff & DC & TC & RR & Vector \\
\hline DC & 1 & 0.14 & 0.14 & 0.07 \\
TC & 7.00 & 1.00 & 0.50 & 0.36 \\
RR & 7.00 & 2.00 & 1.00 & 0.57 \\
\hline CR Value: $0.05<0.10$ (consistent) & & & \\
\hline Effective Communication for & & & Priority \\
researchers & DC & TC & RR & Vector \\
\hline DC & 1 & 0.13 & 0.14 & 0.06 \\
TC & 8.00 & 1.00 & 0.50 & 0.37 \\
RR & 7.00 & 2.00 & 1.00 & 0.56 \\
\hline CR Value: $0.07<0.10$ (consistent) & & & \\
\hline \hline
\end{tabular}

Table 8 presents pair-wise comparisons for the three sub-criteria grouped under recognition. These are: financial rewards $(\mathrm{F})$, non-financial rewards $(\mathrm{NF})$, and branding $(\mathrm{B})$. The table reveals that the administrators' feedback ranked $\mathrm{F}$ and NF joint first, with a priority weight of $43 \%$. They were followed by B, with the lowest priority weight of $14 \%$.

Medical staff prefer financial rewards with a weight of $75 \%$, compared to the other sub-criteria for recognition: NF was weighted at $15 \%$, and $\mathrm{B}$ at $10 \%$. The $\mathrm{CR}$ value for these results is $0.8<0.10$, so they are acceptable. Finally, the table presents responses from researchers, which afford the highest priority to B (65\%), followed by NF (25\%), and F (6\% for).

Table 8: Geometric means of pair-wise comparisons of sub-criteria (Recognition) for administrators, medical staff, and medical researchers

\begin{tabular}{lllll}
\hline \hline $\begin{array}{l}\text { Recognition for } \\
\text { administrators }\end{array}$ & F & NF & B & $\begin{array}{l}\text { Priority } \\
\text { Vector }\end{array}$ \\
\hline F & 1 & 1.00 & 3 & 0.43 \\
NF & 1.00 & 1 & 3 & 0.43 \\
B & 0.33 & 0.33 & 1 & 0.14 \\
CR Value: $0.00<0.10$ (consistent) & & \\
\hline $\begin{array}{l}\text { Recognition for } \\
\text { medical staff }\end{array}$ & F & NF & B & $\begin{array}{l}\text { Priority } \\
\text { Vector }\end{array}$ \\
\hline F & 1 & 7.00 & 6 & 0.75 \\
NF & 0.14 & 1 & 2 & 0.15 \\
B & 0.17 & 0.50 & 1 & 0.10 \\
CR Value: $0.08<0.10$ (consistent) & & \\
\hline Recognition for & \multicolumn{7}{r}{} & NF & B & $\begin{array}{l}\text { Priority } \\
\text { researchers }\end{array}$ \\
\hline F & 1 & 0.14 & 0.11 & 0.06
\end{tabular}




\begin{tabular}{lrrll}
$\mathrm{NF}$ & 7.00 & 1 & 0.33 & 0.29 \\
$\mathrm{~B}$ & 9.00 & 3.00 & 1 & 0.65 \\
\hline CR Value: & $0.08<0.10$ (consistent) & & \\
\hline \hline
\end{tabular}

The comparison for sustainable practices features three sub-criteria: guidelines and empowerment (GE), work ethics (WE), and social responsibility (SR). In the administrators' judgment, the most important criterion was SR (53\%), followed by WE at 33\% and, last, by GE at 14\%. Medical staff responses ranked WE as the most preferred criterion (78\%), followed by GE, with a weight of $15 \%$, and SR at $7 \%$. The high rating of work ethics by medical staff appears to confirm the delicate work environment of medical teams, who deal with human lives on a daily basis.

Medical researchers also rank WE highest at 59\%. This, too, can be seen as a reflection of the centrality of ethics in the work environment of researchers. Work ethics was followed by SR at $36 \%$. The least relevant criterion for researchers was GE, with a $5 \%$ rating.

Table 9: Geometric means of pair-wise comparisons of sub criteria (Sustainable Practices) for administrators, medical staff, and researchers

\begin{tabular}{lllll}
\hline \hline $\begin{array}{l}\text { Sustainable } \\
\begin{array}{l}\text { Practices for } \\
\text { administrators }\end{array}\end{array}$ & GE & WE & SR & $\begin{array}{l}\text { Priority } \\
\text { Vector }\end{array}$ \\
\hline GE & 1.00 & 0.33 & 0.33 & 0.14 \\
WE & 3.03 & 1.00 & 0.50 & 0.33 \\
SR & 3.03 & 2.00 & 1.00 & 0.53 \\
\hline CR Value: 0.05 $<0.10$ (consistent) & & \\
\hline $\begin{array}{l}\text { Sustainable } \\
\text { Practices for }\end{array}$ & & & & Priority \\
medical staff & GE & WE & SR & Vector \\
\hline GE & 1.00 & 0.14 & 3.00 & 0.15 \\
WE & 7.00 & 1.00 & 9.00 & 0.78 \\
SR & 0.33 & 0.11 & 1.00 & 0.07 \\
\hline CR Value: $0.08<0.10$ (consistent) & & \\
\hline $\begin{array}{l}\text { Sustainable } \\
\text { Practices for }\end{array}$ & & & & \\
researchers & GE & WE & SR & Priority \\
\hline GE & 1.00 & 0.11 & 0.13 & 0.05 \\
WE & 9.00 & 1.00 & 2.00 & 0.59 \\
SR & 8.00 & 0.50 & 1.00 & 0.36 \\
\hline CR Value: $0.04<0.10$ (consistent) & & \\
\hline \hline
\end{tabular}

Table 10 displays pair-wise comparisons for the three sub-criteria grouped under career development and succession planning. The three sub-criteria are: coaching and mentoring (CM), career path $(\mathrm{CP})$, and capacity building $(\mathrm{CB})$. The table below shows $\mathrm{CB}$ is ranked as the most important criterion by administrators with a priority weight of $49 \%$, followed by CM (31\%) and 
CP (20\%). Instead, medical staff preferences rated CM the highest at 74\%: this is in line with the needs of a medical work environment, training being an essential requirement for clinical staff. The second preference for medical staff is CB (16\%), followed by CP, with a weight of $10 \%$. Medical researchers ranked $\mathrm{CB}$ highest at $79 \%$. This lends credit to the assumption that medical researchers view capacity building as core to their work of inquiry and research. $\mathrm{CB}$ was followed by $\mathrm{CM}$ at $13 \%$, and, last, by $\mathrm{CP}$ at $8 \%$.

Table 10: Geometric means of pair-wise comparisons of sub-criteria (Career Development and Succession Planning) for administrators, medical staff, and medical researchers

\begin{tabular}{|c|c|c|c|c|}
\hline $\begin{array}{l}\text { Career Dev. and Succ. Planning for } \\
\text { administrators }\end{array}$ & $\mathbf{C M}$ & $\mathbf{C P}$ & $\mathbf{C B}$ & $\begin{array}{l}\text { Priority } \\
\text { Vector }\end{array}$ \\
\hline $\mathrm{CM}$ & 1.00 & 2.00 & 0.50 & 0.31 \\
\hline $\mathrm{CP}$ & 0.50 & 1.00 & 0.50 & 0.20 \\
\hline CB & 2.00 & 2.00 & 1.00 & 0.49 \\
\hline \multicolumn{5}{|l|}{ CR Value: $0.05<0.10$ (consistent) } \\
\hline $\begin{array}{l}\text { Career Dev. and Succ. Planning for } \\
\text { medical staff }\end{array}$ & $\mathbf{C M}$ & $\mathbf{C P}$ & $\mathbf{C B}$ & $\begin{array}{l}\text { Priority } \\
\text { Vector }\end{array}$ \\
\hline $\mathrm{CM}$ & 1.00 & 6.00 & 6.00 & 0.74 \\
\hline $\mathrm{CP}$ & 0.17 & 1.00 & 0.50 & 0.10 \\
\hline $\mathrm{CB}$ & 0.17 & 2.00 & 1.00 & 0.16 \\
\hline \multicolumn{5}{|l|}{ CR Value: $0.05<0.10$ (consistent) } \\
\hline $\begin{array}{l}\text { Career Dev. and Succ. Planning for } \\
\text { researchers }\end{array}$ & $\mathbf{C M}$ & $\mathbf{C P}$ & $\mathbf{C B}$ & $\begin{array}{l}\text { Priority } \\
\text { Vector }\end{array}$ \\
\hline $\mathrm{CM}$ & 1.00 & 2.00 & 0.13 & 0.13 \\
\hline $\mathrm{CP}$ & 0.50 & 1.00 & 0.13 & 0.08 \\
\hline $\mathrm{CB}$ & 8.00 & 8.00 & 1.00 & 0.79 \\
\hline
\end{tabular}

The final step in the AHP methodology is to develop an overall priority ranking of the 19 subcriteria, by multiplying the rankings for the sub-criteria with the criteria priority matrix (Figure 2), for each of the three sample groups considered in this paper. For the administrators' group (Figure 3a), delegation (D) scores highest with a weight of 59\%. This sub-criterion belongs to the parent category of involvement and empowerment, which administrators ranked second to last in the matrix of the main criteria (Table 2). Dual communication (DC) features close in second place, with an overall priority of 57\%. This variable belongs to the parent category of effective communication, the least important amongst the main criteria. Third, comes social responsibility (SR) at 53\%, followed by capacity building (CB) at an overall priority of $49 \%$. Financial and nonfinancial rewards had equal scores of $43 \%$, and informal gathering a weight of $42 \%$. 
Figure 3a: Overall Priorities for Administrators

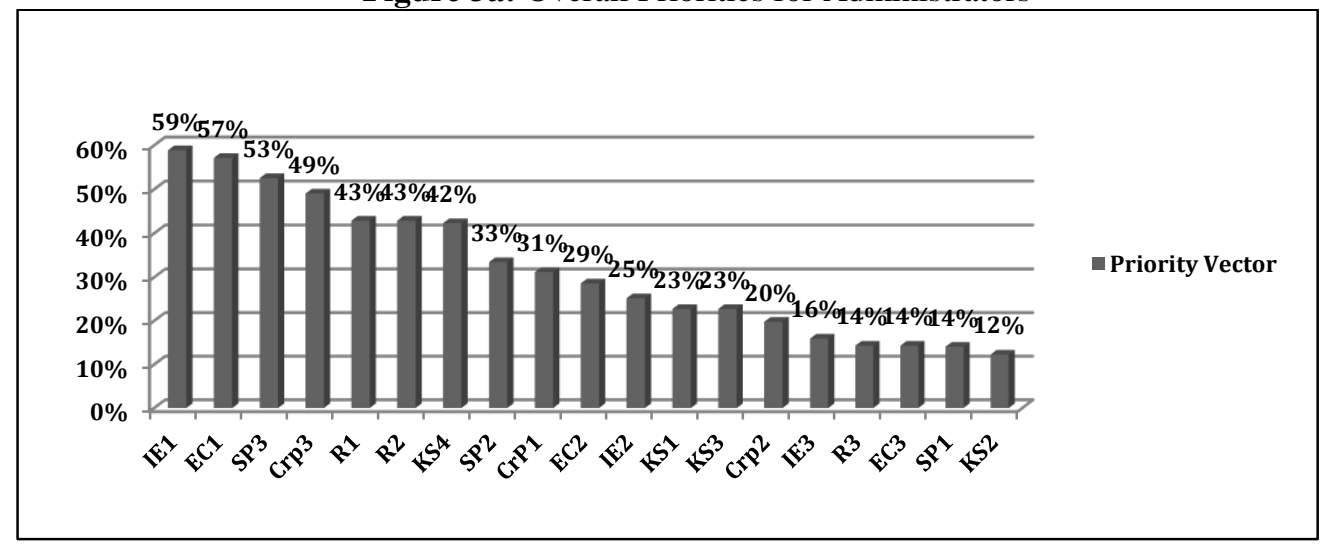

In the medical staff group (Figure 3b), three sub-criteria rank joint first with a score of $75 \%$. These are: coaching and mentoring (CrP1), guidelines and empowerment (SP1), and financial rewards (R1). They are followed by team building (KS2), with a weight of $63 \%$. The next ranked criterion at $57 \%$ concerns roles and responsibilities, after which comes engagement (56\%).

Figure 3b: Overall Priorities for Medical Staff

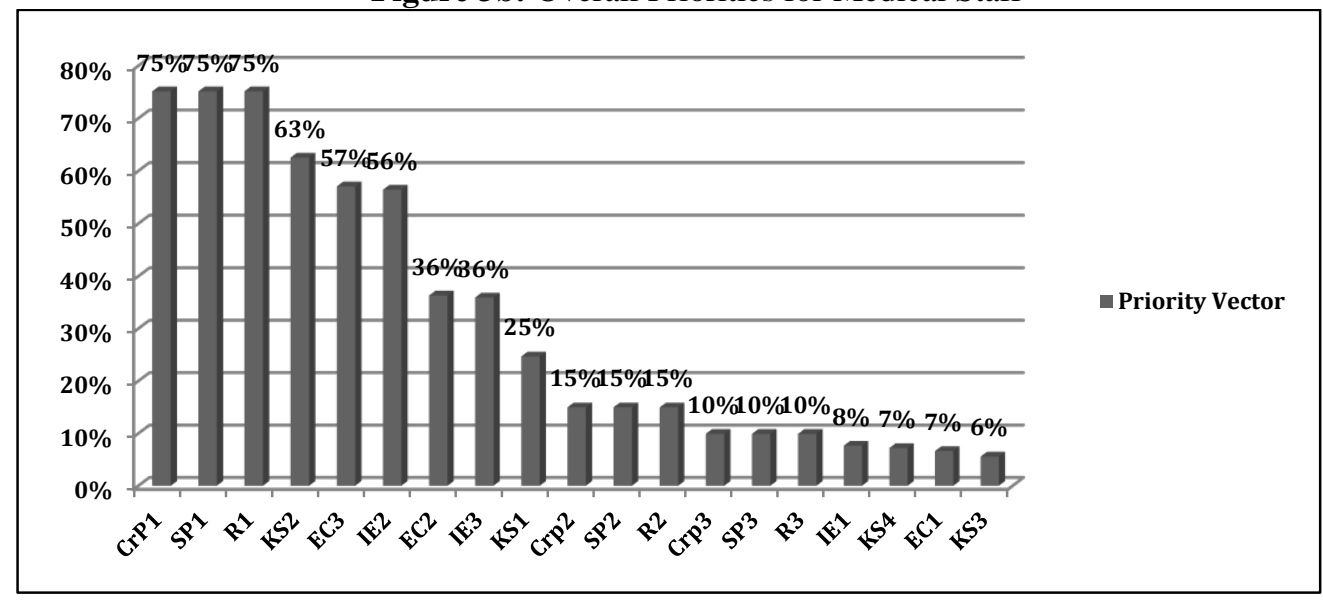

Figure $3 \mathrm{c}$ charts the overall priorities gleaned from the feedback of medical researchers. Capacity building (Crp3) records the highest priority at 79\%. Then, comes delegation (IE1) with a reported weight of $78 \%$. These two criteria rank highest, with a mere $1 \%$ of difference between them. The next factor for the researchers' group is branding (R3), at 65\%. Communication of a brand image for the employer, along with its distinctive features, is acknowledged as being important to counteract high turnover intentions amidst employees (Kashyap \& Rangnekar, 2014; Singh et al., 2012). The next ranked factors are work ethics (SP2) with a score of 59\%, organization culture (KS1) at 58\%, and roles and responsibilities (EC3) with a weight of 56\%. 
Figure 3c: Overall Priorities for Researchers

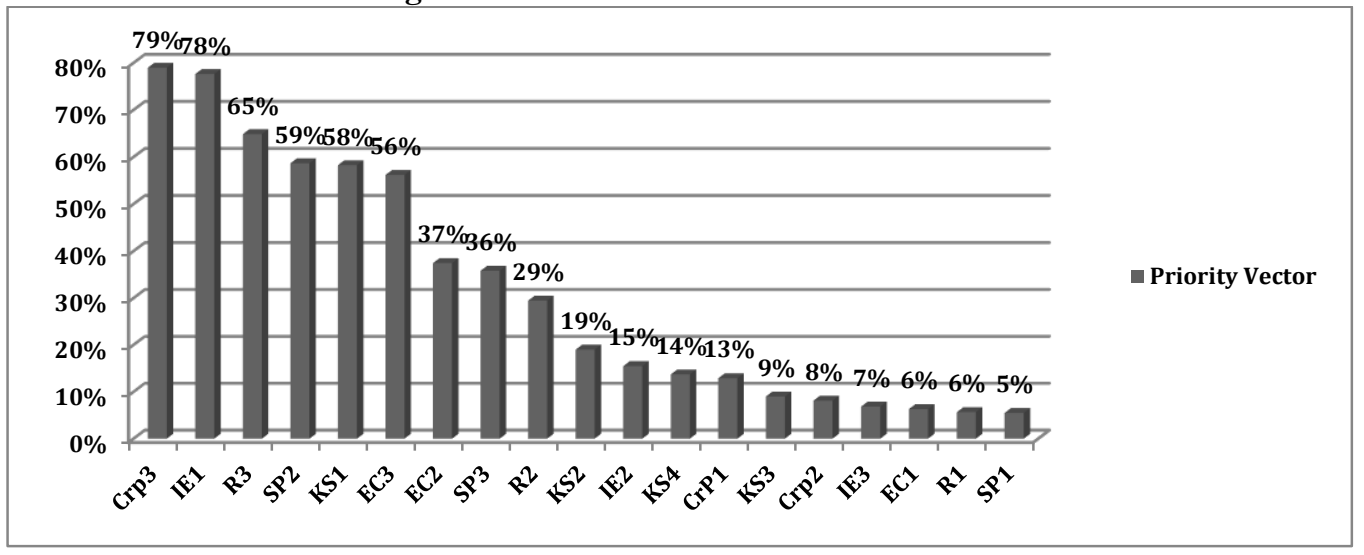

\section{CONCLUSIONS, IMPLICATIONS AND LIMITATIONS}

\subsection{Conclusion}

According to publications of the Health Authority of Abu Dhabi (2012), the healthcare sector in the Emirate of Abu Dhabi has been expanding steadily since 2008. This has led to the inflow of expert workforce operating in the private sector or working with public healthcare providers. The healthcare boom has brought to the fore the challenges, for public healthcare organizations, of attracting suitable employees, as well as keeping existing talent.

Our literature review has shown that organizational culture, which impacts the working environment, displays different dimensions that contribute to creating a passionate workplace, conducive to managing and sustaining the retention of talent. On that basis, this paper constitutes an attempt to contribute to the question of how to manage and sustain retention rates at public healthcare organizations.

For this purpose, this study has adopted an AHP framework comprising of 19 talent retention practices in the healthcare sector, which might influence employees' decisions to leave, or stay in, their current posts. Findings from our empirical research show that management in healthcare organizations puts more emphasis on delegation, as a major factor affecting career decisions. Delegation was ranked highly amongst the proposed criteria for talent retention both by administrators and by medical researchers. An explanation for this might be that psychological empowerment involves individuals in organizational decision-making, generating a sense of control and independence (Iqbal \& Hashmi, 2015; Parwez, 2013; Krishnan et al., 2013). Still, delegation seemed to matter little to respondents from the medical staff group. This is likely due to the horizontal nature of communication and role allocation in clinical teams. While delegation was a highly prized factor by management in healthcare organizations, it was followed by dual (interpersonal) communication and social responsibility as the top three highest priorities for management. Talented professionals at healthcare institution usually work in groups with different allocated tasks. In this respect, delegation helps explore the talent that people have, and so helps 
enhance performance. According to Brunges (2014), hospitals perform better over time in virtually every measurable category when employees are engaged with what they are doing and committed to their jobs. Findings from our inquiry supply healthcare organizations with a knowledge base on which they might proceed to test the results of this paper and gauge whether they might be confirmed at one of their establishments. In case of successful feedback, those practices may then be rolled out institution-wide, based on the outcome of a test implementation.

The pair-wise comparisons of talent retention practices within the administrators group placed dual communication in second place, whereas it was one of the least important attributes for medical staff and researchers. Miscommunication usually affects teamwork negatively and ends up creating a disengaged work environment. The ensuing drop in overall performance can be a factor pushing talented staff to search for better opportunities outside of their institution. The efficiency and quality of work might drop, and this is what administrators try to avoid. Instead, role and responsibility allocation is considered one of the top six items by both medical researchers and medical staff. To conclude on this point, the modes of effective communication valued by the remaining groups of participants are different from those appreciated by technical teams and administrators; this is likely due to differences in professional background and business need.

Guidelines and empowerment were shown to be one of the top priorities for the medical staff, but interestingly this criterion ranked as one of the least relevant two for the groups of administrators and medical researchers. This can be explained by the criticality of clinical cases faced daily by medical staff, which motivates an ensuing need for quality standards. Therefore, this might be the probable reasons why guidelines and empowerment matter most to clinical professionals.

Interestingly, social responsibility was the third highest priority impacting on the decisions of talented administrators to leave or stay, more relevant even than financial and non-financial rewards. The quality of organizational results is what defines the working experience and brand. Tobey and Benson (2009) even show that quality improves when social or volunteer engagement is introduced. Our paper confirms this. On this basis, we suggest that retention rates should be assessed before and after the implementation of interventions geared to enhance social responsibility, gauging the impact of those interventions on service quality.

\subsection{Implications}

This is the first study that focuses specifically on the factors influencing employee retention in the public healthcare sector in the UAE. Our findings support decision-making by policy-makers and HRM strategists, who seek the best techniques for improving organizational culture at their healthcare institutions. The second group of respondents questioned in this study consists of medical staff, for whom the main retention drivers were: coaching and mentoring, guidelines and empowerment, and, last but not least, financial rewards. The third group consisted of medical researchers, whose ranked priorities with a view to remaining in their current post were found to be: building their capabilities, delegation, and branding by the organization. In the light of the problem of talent leakage from public healthcare organizations, the findings of this paper are worth reviewing by public healthcare decision-makers hoping to intervene on those variables most likely to persuade existing talent to remain in their posts. 


\subsection{Limitations and directions for future research}

This paper has only taken into consideration feedback from healthcare professionals, meaning there might be different outcomes if different sectors were investigated. As a direction for further research, it would be worthwhile to pursue the same questions with respect to two or three additional sectors, which would make it possible eventually to compare findings. Such a study would help with the selection of the most effective strategies for retaining talented employees, and sustaining organizational performance and knowledge.

Further studies could be made that used input from different sectors to assess the weight of healthcare professionals' views in determining an overall ranking of factors impinging on employee retention. Alternatively, the methodology used here could be applied to a more restricted sub-group, and then used for comparison with the findings of the present study (which focuses on healthcare professionals as a whole). Last, but not least, another useful direction for future research would come from the triangulation of our findings with those obtained using other experimental or research tools, so as to compare findings.

\section{ACKNOWLEDGEMENT}

The authors would like to thank Luigi Russi, $\mathrm{PhD}$ (www.peerwith.expert//russi) for English language editing.

\section{REFERENCES}

Abd-El-Salam, E. M., Shawky, A. Y., El-Nahas, T., \& Nawar, Y. S. (2013). The relationship among job satisfaction, motivation, leadership, communication, and psychological empowerment: An Egyptian case study. SAM Advanced Management Journal, 78(2), 3350.

Akhtar, S., Ding, D. Z., \& Ge, G. L. (2008). Strategic HRM Practices and their impact on company performance in Chinese enterprises. Human Resource Management, 47(1), 15-32.

Al-Aomar, R., \& Hussain, M. (2017). An assessment of green practices in a hotel supply chain: A study of UAE hotels. Journal of Hospitality and Tourism Management, 31, 71-81.

Al Dari, T., Jabeen, F., \& Papastathopoulos, A. (2018). Examining the role of leadership inspiration, rewards and its relationship with contribution to knowledge sharing: Evidence from the UAE. Journal of Workplace Learning, 30(6), 488-512.

Al Hammadi, F., \& Hussain, M. (2019). Sustainable organizational performance: a study of healthcare organizations in the United Arab Emirates. International Journal of Organizational Analysis, 27(1), 169-186.

Al Mehrzi, N., \& Singh, S. K. (2016). Competing through employee engagement: a proposed framework. International Journal of Productivity and Performance Management, 65(6), 831-843.

Al Suwaidi, M., Jabeen, F., Stachowicz-Stanusch, A., \& Webb, M. (2020). Determinants Linked to Executive Succession Planning in Public Sector Organizations. Vision, 24(3), 284-299.

Arora, R. (2012), A research study of factors influencing talent retention in BPO industry. Journal of Strategic Human Resource Management, 1(2), 54-62. 
Badurdeen, F., Wijekoon, K., \& Marksberry, P. (2011). An analytical hierarchy process-based tool to evaluate value systems for lean transformations. Journal of Manufacturing Technology Management, 22(1), 46-65.

BaniMelhem, H., Elanain, H. M. A., \& Hussain, M. (2019). Impact of Human Resource Management Practices on Employees' Turnover Intention in United Arab Emirates (UAE) Health Care Services. In Human Performance Technology: Concepts, Methodologies, Tools, and Applications (pp. 1244-1267). IGI Global.

Barney, J. (1991). Firm resources and sustained competitive advantage. Journal of Management, 17, 99-120.

Beamish, P. W. (1993). The characteristics of joint ventures in the People's Republic of China. Journal of International Marketing, 1, 29-48.

Brunges, M. (2014). Projects for increasing job satisfaction and creating a healthy work environment. AORN Journal, 100(6), 670-681.

Bruntdland, G. H. (1987). Report of the World Commission on Environment and Development: Our Common Future (Annex to General Assembly document A/42/427). New York, NY: United Nations.

Cappelli, P. (2000). A market-driven approach to retaining talent. Harvard Business Review, 78(1), $103-112$.

Cheng, E. W., \& Li, H. (2001). Analytic hierarchy process: An approach to determine measures for business performance. Measuring Business Excellence, 5(3), 30-37.

Davidson, M. G., \& Wang, Y. (2011). Sustainable labor practices? Hotel human resource managers views on turnover and skill shortages. Journal of Human Resources in Hospitality and Tourism, 10(3), 235-253.

Deo, D. (2014). Role of human resource practices on employee retention in institutes of higher learning in Delhi-NCR. Review of HRM, 3, 259-275.

Drake, P. R., Myung Lee, D., \& Hussain, M. (2013). The lean and agile purchasing portfolio model. Supply Chain Management: An International Journal, 18(1), 3-20.

European Foundation for Quality Management Model Criteria (EFQM). (2013). European Foundation for Quality Management Model Criteria. Retrieved from http:// www.efqm.org/efqm-model/model-criteria/

Ewing, M., Pitt, L., \& De Bussy, N. (2002). Employment branding in the knowledge economy. International Journal of Advertising, 21(1), 3-22.

Jabeen, F., Friesen, H. L., \& Ghoudi, K. (2018). Quality of work life of Emirati women and its influence on job satisfaction and turnover intention: Evidence from the UAE. Journal of Organizational Change Management, 31(2), 352-370.

Jabeen, F., Mehmood, K., \& Mehrajunnisa, M. (2020). Strategic drivers to promote employee suggestion schemes in GCC organizations. Evidence-based HRM, 8(3),273-294.

Jabeen, F., \& Al Dari, T. (2020). A framework for integrating knowledge management benefits in the UAE organizations. Knowledge Management Research \& Practice, 1-15.

Federal Competitiveness and Statistics Authority (2020). Sheikh Khalifa issues national law of reading. Retrieved from https://24.ae/article/571506/88/

Francis, A. U. (2014). Human resource management practices and employee retention in Nigeria's manufacturing industries. International Journal of Scientific \& Engineering Research, 5(2), 1741-1754.

Guha, S., \& Chakrabarti, S. (2015). Effects of intrinsic and extrinsic factors on voluntary employee turnover: An alternative exposition. Anvesha, 8(3), 34-41. 
Gulf News (2008). UAE firms grapple with high staff turnover cost. Retrieved from http://gulfnews.com/business/general/uae-firms-grapple-with-high-staff-turnover-cost1.149010

Hanif, M. I., \& Yunfei, S. (2013). The role of talent management and HR generic strategies for talent retention. African Journal of Business Management, 7(29), 2827-2835.

Hausknecht, J., Trevor, C., \& Howard, M. (2009). Unit-level voluntary turnover rates and customer service quality: Implications of group cohesiveness, newcomer concentration, and size. Journal of Applied Psychology, 94(4), 1068-1075.

Health Authority of Abu Dhabi. (2012). Health Statistics 2012. Retrieved from https:// www.scad.gov.abudhabi/Release\%20Documents/Health\%202012\%20English.pdf

Hill, G. C. (2009). The effect of frequent managerial turnover on organizational performance: A study of professional baseball managers. Social Science Journal, 46(3), 557-570.

Hubbard, G. (2009). Measuring organizational performance: Beyond the triple bottom line. Business Strategy and the Environment, 18(3), 177-191.

Hussain, M., Ajmal, M., Khan, M., \& Saber, H. (2015). Competitive priorities and knowledge management: An empirical investigation of manufacturing companies in UAE. Journal of Manufacturing Technology Management, 26(6), 791-806.

Hussain, M., Malik, M., \& Al Neyadi, H. S. (2016). AHP framework to assist lean deployment in Abu Dhabi public healthcare delivery system. Business Process Management Journal, 22(3),546-65.

Ipek, K. T., \& Arzu Kalemci, R. (2012). Organizational and supervisory support in relation to employee turnover intentions. Journal of Managerial Psychology, 27(5), 518-534.

Iqbal, A. (2010). Employee turnover: Causes, consequences and retention strategies in the Saudi organizations. The Business Review, Cambridge, 16(2), 275-281.

Iqbal, J., \& Mahmood, Y. (2012). Reviewing knowledge management literature. Interdisciplinary Journal of Contemporary Research in Business, 4(6), 1005-1026.

Iqbal, S., \& Hashmi, M. S. (2015). Impact of perceived organizational support on employee retention with mediating role of psychological empowerment. Pakistan Journal of Commerce and Social Sciences, 9(1), 18-34.

Ishizaka, A., Pearman, C., \& Nemery, P. (2012). AHPSort: An AHP-based method for sorting problems. International Journal of Production Research, 50, 4767-4784.

Jabbour, C., Santos, F., \& Nagano, M. (2010). Contributions of HRM throughout the stages of environmental management: Methodological triangulation applied to companies in Brazil. International Journal of Human Resource Management, 21(7), 1049-1089.

James, L., \& Mathew, L. (2012). Employee retention strategies: IT industry. SCMS Journal of Indian Management, 9(3), 79-87.

Jennings, P. D., Cyr, D., \& Moore, L. F. (1995). Human resource management on the Pacific Rim: An integration. In L. F. Moore \& P. D. Jennings (Eds.), Human resource management on the Pacific Rim: Institutions, practices, and attitudes (pp. 351-379). Berlin: de Gruyter.

Karam, A. K. D., Ab Yazid, M. S., Khatibi, A. \& Azam, S. F. (2017). Human Resource Management and Talent Management Towards Organizational Success of Aluminum Industry In United Arab Emirates (Uae): A Measurement Model. European Journal of Human Resource Management Studies, 1(1), 1-21.

Kasekende, F., Byarugaba, K. J., \& Nakate, M. (2014). Employee satisfaction: Mediator of organizational service orientation and employee retention. Journal of Business and Management, 19(3), 41-61. 
Kashyap, V., \& Rangnekar, S. (2014). The moderating role of servant leadership: Investigating the relationships among employer brand perception and perceived employee retention. Review of HRM, 3, 105-118.

Kassem, R., Ajmal, M. M., \& Khan, M. (2016). The relationship between organizational culture and business excellence: Case study from United Arab Emirates. International Journal of Information Systems in the Service Sector, 8(3), 16-35.

Keelson, S. A. (2014). The moderating role of organizational capabilities and internal marketing in market orientation and business success. Review of Business and Finance Studies, 5(1), $1-17$.

Khan, N. (2018, September 21-22). Does Training \& Employee Commitment Predict Employee Retention? In International Conference on Management and Information Systems. Chitkara University, Thailand.

Krishnan, L. R. K., Warier, S., \& Kanaujia, K. (2013). An empirical examination of performance management on employee retention. International Journal of Research in Commerce and Management, 4(1), 148-156.

Laddha, A., Singh, R., Gabbad, H., \& Gidwani, G. D. (2012). Employee retention: An art to reduce turnover. International Journal of Management Research and Review, 2(3), 453-458.

Liberatore, M. J. \& Nydick, R. L. (2008). The analytic hierarchy process in medical and health care decision making: A literature review. European Journal of Operational Research, 189(1), 194-207.

Mehrajunnisa, M., \& Jabeen, F. (2020). Antecedents to employee suggestion schemes: the study of UAE. The TQM Journal, 32(3),497-519.

Morris, S., Hammond, R., \& Snell, S. (2014). A micro foundations approach to transnational capabilities: The role of knowledge search in an ever-changing world. Journal of International Business Studies, 45(4), 405-42.

Muthuveloo, R., Basbous, O. K., Ping, T. A., \& Long, C. S. (2013). Antecedents of employee engagement in the manufacturing sector. American Journal of Applied Sciences, 10(12), $1546-1552$.

Mutsuddi, I. (2016). Employee retention and engagement practices in the healthcare sector. Delhi Business Review, 17(1), 65-78.

Nasrallah, T. (2020). COVID-19: Sheikh Mohamed Bin Zayed commends COVID-19 relief teams. Retrieved from https://gulfnews.com/uae/government/covid-19-sheikh-mohamed-binzayed-commends-covid-19-relief-teams-1.1586632104696

Nuaimi, M. A., \& Jabeen, F. (2020). A study of factors influencing knowledge transfer in organisations in the United Arab Emirates. International Journal of Knowledge Management Studies, 11(2), 170-189.

Ohunakin, F., Adeniji, A. A., Ogunlusi, G., Igbadumhe, F., \& Sodeinde, A. G. (2020). Talent retention strategies and employees' behavioural outcomes: empirical evidence from hospitality industry. Business: Theory and Practice, 21(1), 192-199.

Oladapo, V. (2014). The impact of talent management on retention. Journal of Business Studies, $5(3), 19-36$.

Parwez, S. (2013). An assessment of Indian higher education in reference to knowledge acquisition and retention management. International Journal of Organizational Behavior and Management Perspectives, 2(3), 551-555.

Saaty, T. L. (1980). The Analytic Hierarchy Process: Planning, Priority Setting, Resources Allocation. New York, NY: McGraw-Hill. 
Saaty, T. L. (1990). How to make a decision: the analytic hierarchy process. European Journal of Operational Research, 48(1), 9-26.

Saaty, T. L. (2012). Decision Making for Leaders: The Analytical Hierarchy Process for Decision in a Complex World. Pittsburgh, PA: RWS Publications.

Samuel, M. O., \& Chipunza, C. (2009). Employee retention and turnover: Using motivational variables as a panacea. African Journal of Business Management, 3(8), 410-415.

Singh, A., Jones, D. B., \& Hall, N. (2012). Talent management: A research based case study in the GCC region. International Journal of Business and Management, 7(24), 94.

Subramanian, N., \& Ramanathan, R. (2012). A review of applications of analytic hierarchy process in operations management. International Journal of Production Economics, 138(2), 215241.

Suliman, A. M., \& Obaidli, H. A. (2011). Organizational climate and turnover in Islamic banking in the UAE. International Journal of Islamic and Middle Eastern Finance and Management, 4(4), 308-324.

Surbakti, H., \& Ta'a, A. (2016, August 29-30). Improving employees retention rate through knowledge management and business intelligence components. Paper presented at the Knowledge Management International Conference (KMICe). Chiang Mai, Thailand.

Suresh, A. (2014). Synthesis of knowledge through responsiveness, recognition, formation, attraction and retention: An empirical approach. The IUP Journal of Knowledge Management, 12(1), 53-61.

Suresh, L., \& Krishnaraj, S. (2015). A study on the importance of employee retention in pharmaceutical sector in India. International Journal of Pharmaceutical Sciences Review and Research, 32(1), 108-111.

Tobey, D., \& Benson, P. (2009). Aligning Performance: The End of Personnel and the Beginning of Guided Skilled Performance. Management Revue, 20(1), 70-89.

Ton, Z., \& Huckman, R. S. (2008). Managing the impact of employee turnover on performance: The role of process conformance. Organization Science, 19(1), 56-68.

Vinodh, S., \& Joy, D. (2012). Structural equation modeling of sustainable-manufacturing practices. Clean Technology Environment Policy, 14(1), 79-84.

Wenmi Net. (2007). The localization of human resource management of MNCs in China and its impact and implications. Retrieved from http://www.wenmil14.com/wenmi/ lunwen/jingjilunwen/2007-07-26/20070726109063.html

Weyman, A., Roy, D., \& Nolan, P. (2019). One-way pendulum? -Staff retention in the NHS: Determining the relative salience of recognised drivers of early exit. International Journal of Workplace Health Management, 13(1), 45-60.

Zafar, S., Siddiqui, D.A. (2019). Factors Affecting Employees Performance and Retention: A Comparative Analysis of Banking and Educational Sector of Karachi. Business Management and Strategy, 10(1), 93-124. 